\title{
POTENCIAL FENÓLICO DE UVAS DA VARIEDADE MERLOT E SUA CORRELAÇÃO COM A COMPOSIÇÃO FENÓLICA DOS VINHOS ${ }^{1}$
}

\author{
ALINE DE OLIVEIRA FOGAÇA² \& CARLOS EUGENIO DAUDT³
}

RESUMO -Este trabalho foi realizado com o objetivo de avaliar a maturação fenólica e industrial de uvas da variedade Merlot produzidas na região da Campanha Gaúcha e Serra Gaúcha-RS, e avaliar a correlação entre o potencial fenólico estimado nessas uvas com a composição fenólica dos vinhos resultantes. Os resultados obtidos demonstraram que a maturação industrial e fenólica tem grande variabilidade entre os vinhedos estudados, especialmente em relação ao conteúdo de antocianinas, deixando clara a influência da localização do vinhedo nas características das uvas, bem como a influência da safra. O grau de maturação da uva, analisado através da \%IMC, influencia no conteúdo de compostos fenólicos totais e taninos encontrados nos vinhos resultantes. A análise do potencial fenólico das uvas está correlacionada ao conteúdo de polifenóis, à porcentagem da cor devido a pigmentos poliméricos e à quantidade de procianidinas presentes nos vinhos resultantes, sendo assim uma ferramenta útil para a tomada de decisão do melhor momento da colheita.

A intensidade de cor, o conteúdo de antocianinas e a porcentagem de cor devido a antocianinas poliméricas nos vinhos, juntamente com o teor de polifenóis totais na uva foram os principais parâmetros que diferenciaram as uvas e os vinhos estudados.

Termos para indexação: maturação fenólica, cor, antocianinas, taninos, maturação industrial.

\section{PHENOLIC POTENTIAL OF MERLOT GRAPES AND ITS CORRELATION WITH WINE PHENOLIC COMPOSITION}

\begin{abstract}
This study was carried out in order to evaluate the phenolic and industrial ripeness of Merlot grapes produced in the "Campanha Gaúcha" and "Serra Gaúcha" regions, RS, and evaluate the correlation, if any, between the phenolic potential estimated in Merlot grapes and the phenolic composition of the resulting wines. The results showed that the industrial and the phenolic maturity had a great variability among the vineyards studied; the grape ripeness degree, analyzed by \%IMC, has an influence in the amount of total phenols and tannins in the resulting wine. The analysis of grape phenolic's potential is related to the content of polyphenols, the percentage of color due to polymeric pigments and the procyanidins content in the future wines, making it a useful tool for the decision of the best time of harvest. The color intensity, the anthocyanin content and the percentage of color due polymeric anthocaynins in the wines and the grape total phenolic content were the main parameters that allowed to distinguish the wines and grapes studied.

Index terms: Phenolic ripennes, color, anthocyanins, procyanidins, industrial ripeness.
\end{abstract}

\footnotetext{
'(Trabalho 141-14). Recebido em: 28-04-2014. Aceito para publicação em: 20-05-2015.

${ }^{2}$ Professora adjunta, Eng. Agronoma, Centro Universitário Franciscano, Rua dos Andradas, 1614, Centro, CEP 97010-032, Santa Maria, RS, Brazil, e-mail: alinefogaca@gmail.com

${ }^{3}$ Professor Titular, Departamento de Ciência e Tecnologia dos Alimentos, Universidade Federal de Santa Maria - UFSM, Km 9, Camobi, CEP 97119-900, Santa Maria, RS, Brazil, ced.voy@gmail.com
} 


\section{INTRODUÇÃO}

Os produtores brasileiros estão buscando produzir vinhos de qualidade, sendo que o momento de colheita da uva influencia diretamente nas características dos vinhos elaborados. No entanto, a maioria das vinícolas brasileiras ainda determina o momento da colheita somente de acordo com os parâmetros da maturação industrial (açúcar, acidez titulável e pH da polpa); uma alternativa apropriada seria usar a análise da maturação fenólica junto com a industrial para determinar o momento da colheita.

Um dos fatores mais importantes que afetam a qualidade do vinhos é a maturação fenólica das uvas, sendo que esta maturação se refere à quantidade de fenóis presentes na casca, polpa e sementes. Uma uva matura é caracterizada por cascas ricas em antocianinas e taninos complexos e inativos, e sementes com um baixo conteúdo de taninos polimerizados que reagem fortemente com proteínas. Por outro lado, uvas imaturas possuem baixas concentrações de antocianinas nas cascas e taninos relativamente simples que não perderam sua reatividade, e sementes com alta concentração de taninos pouco polimerizados, entretanto altamente reativos (RIBÉREAU-GAYON et al., 2006).

É importante saber a quantidade desses fenóis que podem ser extraídos da uva para o vinho (NOGALES BUENO et al., 2014). A extratibilidade dos compostos fenólicos das cascas depende significativamente da maturação da uva. De acordo com Hernandez-Hierro et al. (2014), uvas mais maduras apresentam alta degradação da parede celular, resultando em alto grau de extração dos compostos, sendo que o aumento da extratibilidade das antocianinas durante o amadurecimento das uvas é consequência da degradação celular por enzimas pectinolíticas (RIBÉREAU-GAYON et al., 2006).

É importante ressaltar que a composição fenólica da uva depende de fatores intrínsecos, tais como a variedade (ĆURKO et al., 2014) e fatores extrínsecos, tais como o clima (ZHANG et al., 2014), entre outros.

Várias metodologias foram desenvolvidas na tentativa de estimar a maturação fenólica das uvas. Lasanta et al. (2014) mostraram que a maturação da uva influencia fortemente na composição do vinho e que é possível estabelecer parâmetros-chave que deverão ser monitorados durante o processo de maturação da uva para identificar o momento ideal de colheita para obter vinhos de qualidade. $\mathrm{O}$ método mais utilizado foi desenvolvido por Glories e Agustín em 1993, e é descrito por Saint-Cricq et al. (1998) e por Ribéreau-Gayon et al. (2006). Nesta metodologia, são realizadas duas macerações com a uva triturada, uma a $\mathrm{pH} 1,0$ e outra a $\mathrm{pH} 3,6$, por 4 horas sob agitação. $\mathrm{O}$ índice de maturação celular, também conhecido como índice de extratibilidade, baseia-se no conceito de que, com $\mathrm{pH}, 1,0$ há uma desorganização completa das membranas dos vacúolos, o que facilita a liberação dos compostos fenólicos. No pH 3,6, a degradação natural das células é respeitada, situação similar ao que ocorre no mosto durante a vinificação (SAINT-CRICQ et al., 1998).

Este trabalho foi realizado com o objetivo de avaliar a maturação fenólica (através da metodologia descrita acima) e industrial de uvas da variedade tinta Merlot, produzidas em duas regiões vitícolas distintas do Estado do Rio Grande do Sul e avaliar a correlação entre o potencial fenólico estimado nas uvas com a composição fenólica e a cor dos vinhos resultantes, utilizando metodologias simples e muito utilizadas ainda hoje, disponíveis nas indústrias de produção de vinhos brasileiros, permitindo uma análise global e rápida das características fenólicas dos vinhos.

\section{MATERIAL E MÉTODOS}

Amostras de uvas da variedade tinta Vitis vinifera Merlot foram coletadas no momento da colheita industrial (utilizando os parâmetros acidez titulável, $\mathrm{pH}$ e teor de sólidos solúveis totais), em duas safras, 2010 e 2011, e as datas encontram-se na Tabela 1. A área selecionada para o experimento era composta por 1.500 plantas. A data da colheita foi a mesma utilizada pela vinícola para colheita comercial, a qual levou em consideração não só os parâmetros já mencionadas, mas também as condições climáticas de cada ano.

A amostragem, em triplicata, foi realizada extraindo 3 a 5 bagas por cacho, na zona média de altura das videiras e alternadamente das duas metades inferior e superior dos cachos, totalizando 250 bagas por amostra. Os vinhedos amostrados estão localizados em duas regiões bem distintas: Serra Gaúcha (município de Bento Gonçalves) e Campanha Gaúcha (município de Dom Pedrito). Os vinhedos chamados 1 e 4 estão localizados na região da Campanha Gaúcha, e os vinhedos 2 e 3 estão localizados na região da Serra Gaúcha.

As análises espectrofotométricas foram realizadas utilizando cubetas de quartzo de 1 e/ou 10 mm de caminho ótico, de acordo com o comprimento de onda a ser lido, em um espectrofotômetro UV 11000, marca Pró Análise (UV/Visível). A determinação do potencial polifenólico foi calculado através dos índices propostos por González-Neves et al. (2003), 
em triplicata. A partir dessas análises, calcularam-se o índice de maturidade celular (IMC\%) e a proporção de taninos nas sementes e nas cascas. Análises de acidez titulável (g.L -1 $^{-1}$ e ácido tartárico), $\mathrm{pH}$ e sólidos solúveis ( ${ }^{\circ}$ Brix) foram realizadas de acordo com a metodologias padrões (ZOECKLEIN et al., 2001); o índice de maturação industrial foi calculado da seguinte forma: valor do ${ }^{\circ}$ Brix dividido pelo valor da acidez (g.L $\mathrm{L}^{-1}$ de ácido tartárico).

Após a colheita, as uvas amostradas para a análise da maturação industrial e fenólica foram utilizadas para realização de microvinificações. As microvinificações foram realizadas em triplicata, em recipientes com capacidade de 5 litros. Após o desengace e o esmagamento, foi realizada a sulfitagem (50 mg.L $\mathrm{L}^{-1}$ de $\mathrm{SO}_{2}$ ) e a inoculação de levedura Saccharomyces cerevisiae da marca Perdomini ${ }^{\circledR}$ (Blastocel Grand Cru), na dosagem de 20 g.hL . $^{-1}$ A maceração foi realizada durante 8 dias, e a temperatura de fermentação foi controlada entre 25 a $28^{\circ} \mathrm{C}$, sendo realizadas nesse período duas remontagens diárias. Ao término da fermentação alcoólica, foi realizada nova sulfitagem $\left(20 \mathrm{mg} . \mathrm{L}^{-1}\right.$ de $\mathrm{SO}_{2}$ ) e trasfega, com separação das borras. Após 2 meses, foi realizada nova trasfega e engarrafamento (PSZCZÓLKOWSKI;LECCO, 2011).

A determinação do potencial polifenólico foi realizada através da metodologia proposta por Glories e Augustin (1993), calculando os índices como propostos por González-Neves et al. (2003). As análises foram realizadas a partir de duas macerações das uvas inteiras trituradas, realizadas durante 4 horas, com soluções de $\mathrm{pH}$ 1,0 e 3,2, respectivamente. Os macerados foram filtrados e centrifugados por 3 minutos, a $3.000 \mathrm{rpm}$. Nos extratos obtidos através das duas macerações, foi determinado o índice de polifenóis totais (medição da absorbância a $280 \mathrm{~mm}$ após diluição $1: 100$, conforme descrito por RIBEREAU-GAYON et al., 2006) e antocianinas por branqueamento por bissulfito $(\mathrm{ApH}$ 1,0 e ApH 3,2). A partir dessas análises, calculam-se o índice de maturidade celular, também chamado de extratibilidade de antocianinas (EA) e o índice de maturidade das sementes (MP), mediante as equações 1 e 2, apresentadas abaixo (RIBEREAU-GAYONET al., 2006).

$$
\mathrm{EA}(\%)=\frac{(\mathrm{ApH} 1-\mathrm{ApH} 3,2) \times 100}{\mathrm{ApH} 1}
$$

$\mathrm{Mp}(\%)=[\mathrm{IPT} \mathrm{pH} 3,2-(\mathrm{ApH} 3,2 \times 40) / 1000] \times 100(2)$ IPT $\mathrm{pH} 3,2$
A equação 3 foi utilizada para calcular a porcentagem dos teores de taninos das cascas, de acordo com Glories e Augustin (1993):

$\%$ taninos nas cascas $=((\mathrm{ApH} \mathrm{3,2} \times 40) / 1.000) /$ IPT) * 100

A quantificação de fenóis totais foi realizada pelo método de Folin-Ciocalteau (mg. $\mathrm{L}^{-1}$ de ácido gálico); a de antocianinas, pelo método de branqueamento por bissulfito (mg. $\mathrm{L}^{-1}$ de malvidina3-glucosídeo), e a de procianidinas, pelo método de hidrólise ácida (g. $\mathrm{L}^{-1}$ de cloreto de ciadinina). Os índices de cor (intensidade de cor e tonalidade) foram medidos diretamente, sem diluição da amostra, através da leitura da absorbância das amostras, nos comprimentos de onda de 420; 520 e $620 \mathrm{~nm}$. O índice de polifenóis totais foi calculado a partir da absorbância de uma amostra diluída 1:100 a $280 \mathrm{~nm}$; as metodologias acima foram descritas por Ribéreau-Gayon et al. (2006). A metodologia proposta por Boulton (1996) estima a cor devido a antocianinas monoméricas $(\% \mathrm{M})$, antocianinas copigmentadas $(\% \mathrm{C})$ e antocianinas poliméricas $(\% \mathrm{P})$. Resumidamente, o $\mathrm{pH}$ dos vinhos foi ajustado a 3,6 (para padronização) e filtrados em membrana $(0,45 \mu \mathrm{m})$. Todas as leituras de absorbâncias foram realizadas a $520 \mathrm{~nm}$. Em uma alíquota de vinho de 2 $\mathrm{mL}$, foi adicionado $20 \mu \mathrm{l}$ de acetaldeído a $10 \%$; após 45 minutos, foi realizada a leitura da absorbância $\left(A^{\text {acet}}\right)$. Numa segunda alíquota de $100 \mu \mathrm{l}$, foram adicionados $1.900 \mu 1$ de solução tampão a $\mathrm{pH} 3,6$ e realizada a leitura da absorbância $\left(\mathrm{A}^{20}\right)$. Numa terceira alíquota de $2 \mathrm{~mL}$, foram adicionados 160 $\mu 1$ de solução de metabissulfito de potássio a $20 \%$, e realizada a leitura da absorbância $\left(\mathrm{A}^{\mathrm{so} 2}\right)$. Os cálculos foram realizados a partir das equações 3,4 e 5 :

$\%$ da cor devido à Copigmentação:

$\left(\mathrm{A}^{\text {acet }}-\mathrm{A}^{20}\right) / \mathrm{A}^{\text {acet }}$

$\%$ da cor devido a antocianinas moméricas:

$\left(\mathrm{A}^{20}-\mathrm{A}^{\mathrm{SO}}\right) / \mathrm{A}^{\text {acet }}$

$\%$ da cor devido a antocianinas poliméricas: $\left(\mathrm{A}^{\mathrm{SO} 2}\right) / \mathrm{A}^{\text {acet }}$

Não foram utilizadas técnicas com uso de cromatografia líquida por não serem metodologias usadas normalmente pela indústria vinícola brasileira.

A análise estatística foi realizada através do programa Statistica 7.0 (StatSoft), os dados foram submetidas à análise de variância (ANOVA), e as médias, separadas pelo teste de Tukey, a 5\%. A 
partir do agrupamento dos dados de cada vinho, foi calculado o coeficiente de correlação de Pearson, e sua significância foi verificada pelo teste t de Student, a $5 \%$ de probabilidade. A análise de componente principal foi realizada através do software Pirouette 4.0 (Infometrix, Woodinville, EUA), sendo os dados autoescalados.

\section{RESULTADOS E DISCUSSÃO}

A maturação industrial e fenólica, determinada pelas características químicas das uvas, é apresentada na Tabela 2. De acordo com Rizzon et al. (1998), as características do solo e do clima das regiões vitícolas da Serra Gaúcha e da Campanha Gaúcha originam uvas e vinhos que diferem significativamente quanto à acidez, o que confirma os dados obtidos neste estudo. A maturação industrial é considerada adequada quando a relação entre o açúcar e a acidez ( ${ }^{\circ}$ Brix/acidez) atinge valores entre 3 e 5 . Os dados deste estudo mostram que, na safra de 2011, todas as uvas analisadas apresentaram valores nesta faixa (entre 3,2 e 5,1); entretanto, na safra de 2010, apenas as uvas do vinhedo 1 atingiram a maturação industrial adequada (vinhedo 1, com 3,8).

De todos os parâmetros analisados para prever o potencial fenólico das uvas, o teor de antocianinas potenciais (ApH1), (Tabela 2), destaca-se pela grande variação apresentada entre as amostras (189,3 a 522,7 mg.L. $\mathrm{L}^{-1}$ malvidina glucosídeo), inclusive na análise do mesmo vinhedo ( 1 e 2 ), por dois anos consecutivos. Os teores de antocianinas potenciais (ApH1) e extraíveis $(\mathrm{ApH} 3,2)$ parecem não ter correlação com os valores de acidez, ou seja, a quantidade de antocianinas não possui relação direta com o aumento da maturação industrial, uma vez que um adequado índice de maturação industrial não corresponde a um alto teor de antocianinas.

A localização do vinhedo parece ter uma influência maior, uma vez que os vinhedos amostrados se encontram em regiões com climas distintos. De acordo com Daudt et al. (1973) e Motta (2003), a região da Campanha Gaúcha (município de Dom Pedrito) apresenta maior insolação e menor quantidade de chuva no período que vai do início ao final da maturação da uva, em comparação com a Serra Gaúcha (município de Bento Gonçalves). O Tabela 2 apresenta a média mensal histórica para precipitação e temperatura, confirmando que a região da Campanha apresenta temperaturas mais altas e menor precipitação (foram utilizados os dados do município de Bagé pela proximidade com Dom Pedrito, pois a mesma não teve dados disponíveis). Spayd et al. (2002), trabalhando com uvas da variedade Merlot, observaram que temperaturas excessivamente altas reduziram a acumulação de antocianinas nas cascas, embora o calor seja necessário para a síntese desses compostos. Assim, os menores teores de antocianinas encontrados nos vinhedos localizados em Dom Pedrito (vinhedos 1 e 4), quando comparados aos vinhedos de Bento Gonçalves, estão associados ao clima dessas regiões.

Por outro lado, nem sempre uma grande quantidade de antocianinas na uva significa grande quantidade no vinho correspondente. $\mathrm{O}$ índice de maturidade celular (IMC\%) tem um papel importante nesse contexto; quanto menor o valor desse índice, maior é a extratibilidade das antocianinas das cascas. $\mathrm{O}$ vinhedo 4, com menor quantidade de antocianinas (147,7 mg. $\mathrm{L}^{-1}$ malvidina glucosídeo), é o que apresenta o melhor IMC \% $(22,1)$, demonstrando que um alto teor de antocianinas nem sempre corresponde a uma extratibilidade adequada. Inúmeros fatores interferem na extração das antocianinas das cascas; Ortega-Regules e Bel (2008) propuseram que uma alta extratibilidade de antocianinas pode ser encontrada associada com baixas concentrações de galactose, celulose, ramanose e xilose, e com a presença de pectinas de baixo teor de metoxilação.

O teor de fenóis totais (expresso pelo IPT) tem sido utilizado pela indústria como um fator importante na determinação da época de colheita, relacionado com o acúmulo de antocianinas. No entanto, os dados obtidos (Tabela 3 ) não confirmam essa relação direta entre IPT e antocianinas totais. Entretanto, nestas relações, não pode ser esquecido o papel dos taninos. Segundo Kennedy (2008), o aumento da quantidade dos taninos é relacionado com o aumento de taninos nas cascas (TC\%). Durante a maturação, espera-se uma diminuição da extratibilidade dos taninos das sementes (TS\%) e um aumento dos mesmos nas cascas (\%TC). Os taninos presentes nas cascas e nas sementes são de tipos diferentes (KENNEDY, 2008), e os índices \% TC e \%TS são apenas uma estimativa, os quais levam em consideração o teor total de fenóis, medido pelo índice IPT. Na Tabela 3, pode ser observado que as uvas de Dom Pedrito (vinhedos 1 e 4) produziram os maiores resultados para TS\% (76,2 e 70,9), o que implica menor \%TC. No final, as uvas de todos os vinhedos estudados apresentaram a proporção de taninos nas sementes superior a $40 \%$, sendo que esta alta proporção parece a característica da variedade Merlot, de acordo com González-Neves et al. (2003).

A Tabela 5 apresenta os dados obtidos na análise dos vinhos elaborados a partir das uvas analisadas na Tabela 4 , todos com 8 dias de maceração e após 6 meses de engarrafamento. A variação nos 
teores de antocianinas, do IPT e do índice de cor, parece estar mais associada às características do ano, uma vez que os maiores valores são encontrados nas amostras originárias do mesmo ano, no caso, da safra de 2011. Já a quantidade de fenóis totais, procianidinas, a porcentagem de antocianinas copigmentadas e a porcentagem de antocianinas monoméricas apresentaram pouca ou nenhuma diferença entre os vinhos.

Analisando apenas os dados dos vinhos elaborados na safra de 2011, o vinho do vinhedo 4, que apresentou o menor teor de antocianinas (ApH1 e ApH3,2) na uva (Tabela 3), é aquele com o maior teor de antocianinas (ANT) (Tabela 4); isto pode ser explicado pelo alto índice de maturação celular (IMC\%) que estas uvas apresentavam no momento da colheita, facilitando a extração desses compostos durante o processo fermentativo. Entretanto, este vinho não apresenta o maior índice de cor. A influência da safra pode ser vista na comparação do índice de cor dos vinhos de 2010 e 2011, dos vinhedos 1 e 2 .

Em relação ao estudo da copigmentação (Tabela 4), a porcentagem de cor devido a antocianinas copigmentadas e poliméricas não diferiu entre os vinhos, ou seja, podemos dizer que esses parâmetros estão mais associados às características da variedade.

Com a finalidade de facilitar a correlação entre o potencial fenólico da uva e o teor de fenóis no vinho, foram calculados os coeficientes de correlação, apresentados na Tabela 5. O índice de polifenóis (IPT) determinado na uva apresentou forte correlação positiva com o teor de polifenóis totais $(0,77)$, com a quantidade de procianidinas $(0,77)$ e com a porcentagem de antocianinas poliméricas $(0,70)$, ambos determinados no vinho. A quantidade de antocianinas extraíveis $(\mathrm{ApH} 3,2)$ apresentou forte correlação com a porcentagem de antocianinas poliméricas; essa correlação é explicada pela capacidade de as antocianinas se ligarem a moléculas de taninos e formarem pigmentos poliméricos (RIBÉREAU-GAYON et al., 2006). No entanto, nenhuma dessas correlações é significativa. Somente o índice de maturidade celular (IMC\%) apresentou correlação positiva com duas variáveis do vinho; sendo uma forte correlação negativa com o teor de polifenóis totais $(-0,91)$ e com a quantidade de taninos $(-0,87)$ medidos no vinho. Pode-se dizer que quanto maior a maturação celular (menor valor de IMC\%), maior é a extração de polifenóis totais e de taninos para o vinho. Esperava-se uma correlação forte com o teor de antocianinas, uma vez que González-Neves et al. (2003), trabalhando com uvas das variedades tintas no Uruguai, observaram que o conteúdo de antocianinas dos vinhos correlacionou-se, significativamente, com todos os índices determinados nas uvas. No entanto, a correlação é fraca para ambas as medidas de antocianinas utilizadas neste estudo, uma vez que a cor de um vinho é resultado não apenas do teor de antocianinas, mas também do tipo de pigmentos poliméricos presentes (RIBÉREAU-GAYON et al., 2006). A falta de correlações fortes e significativas entre a intensidade de cor do vinho e os parâmetros analisados na uvas confirma a complexidade da cor de um vinho, a qual é influenciada por inúmeros fatores.

Os dados das Tabelas 4 e 5 foram agrupados para análise multivariada, utilizando a análise de componente principal como ferramenta estatística, e os resultados são apresentados na Figura 1. O componente principal 1 (que explica $33,0 \%$ da variação), permitiu separar os vinhedos em dois grupos distintos (Figura 1b). As variáveis que mais pesaram para essa separação (Figura 1a) foram o teor de antocianinas, o índice de cor e a porcentagem de antocianinas poliméricas no vinho e o índice de polifenóis na uva, ou seja, esses quatro parâmetros são os principais responsáveis pelas diferenças encontradas nas amostras analisadas. Nesta figura, pode ser observada, também, a separação dos vinhedos 1 e 2 (ambos estudados nos dois anos do experimento), de acordo com a safra, comprovando a influência do clima nas características das uvas e vinhos.

O componente principal 2 (30,7\% da variação) permitiu a separação de acordo com a região em que as uvas são produzidas. Nesse caso, os principais parâmetros são o teor de taninos no vinho (TAN), a proporção de taninos nas sementes (TS\%), o teor de antocianinas potenciais $(\mathrm{ApH} 1,0)$ e o índice de maturação celular (IMC\%), ou seja, as características das uvas são os principais fatores que diferenciam as duas regiões estudadas. 
TABELA 1 - Descrição dos vinhedos utilizados para a realização dos experimentos.

\begin{tabular}{|c|c|c|c|c|}
\hline Vinhedo & Localização & $\begin{array}{c}\text { Safras } \\
\text { Analisadas }\end{array}$ & $\begin{array}{l}\text { Data de } \\
\text { colheita }\end{array}$ & $\begin{array}{c}\text { Coordenadas } \\
\text { Geográficas }\end{array}$ \\
\hline 1 & $\begin{array}{c}\text { Campanha Gaúcha - município de } \\
\text { Dom Pedrito }\end{array}$ & $2010 / 2011$ & $\begin{array}{l}\text { 2010: } 17-02 \\
2011: 28-02\end{array}$ & $\begin{array}{l}30^{\circ} 98^{\prime} 32.8^{\prime \prime} \mathrm{S} \\
54^{\circ} 63^{\prime} 93.6^{\prime \prime} \mathrm{W}\end{array}$ \\
\hline 2 & $\begin{array}{c}\text { Serra Gaúcha - município de Bento } \\
\text { Gonçalves }\end{array}$ & $2010 / 2011$ & $\begin{array}{l}\text { 2010: } 26-02 \\
\text { 2011: } 12-03\end{array}$ & $\begin{array}{l}29^{\circ} 10^{\prime} 63.9^{\prime \prime} \mathrm{S} \\
51^{\circ} 44^{\prime} 81.9^{\prime \prime} \mathrm{W}\end{array}$ \\
\hline 3 & $\begin{array}{c}\text { Serra Gaúcha - município de Bento } \\
\text { Gonçalves }\end{array}$ & 2010 & 2010: 26-02 & $\begin{array}{l}29^{\circ} 20^{\prime} 08.0^{\prime} \mathrm{S} \\
51^{\circ} 55^{\prime} 30.1^{\prime \prime} \mathrm{W}\end{array}$ \\
\hline 4 & $\begin{array}{c}\text { Campanha Gaúcha - município de } \\
\text { Dom Pedrito }\end{array}$ & 2011 & 2011: 21-03 & $\begin{array}{l}31^{\circ} 08^{\prime} 41.0^{\prime \prime} \mathrm{S} \\
54^{\circ} 11^{\prime} 46.9^{\prime \prime} \mathrm{W}\end{array}$ \\
\hline
\end{tabular}

TABELA 2- Temperatura média $\left({ }^{\circ} \mathrm{C}\right)$ e Precipitação média ( $\left.\mathrm{mm}\right)$ mensal, no período histórico de 1961 a 1990, nos municípios de Bagé e Bento Gonçalves.

\begin{tabular}{|c|c|c|c|c|}
\hline \multirow[b]{2}{*}{ Mês } & \multicolumn{2}{|c|}{ Bagé $^{1}$} & \multicolumn{2}{|c|}{ Bento Gonçalves ${ }^{2}$} \\
\hline & $\begin{array}{c}\text { Temperatura } \\
\left({ }^{\circ} \mathrm{C}\right)\end{array}$ & $\begin{array}{c}\text { Precipitação } \\
(\mathrm{mm})\end{array}$ & $\begin{array}{c}\text { Temperatura } \\
\left({ }^{\circ} \mathrm{C}\right)\end{array}$ & $\begin{array}{c}\text { Precipitação } \\
(\mathbf{m m})\end{array}$ \\
\hline Jan. & 24,0 & 115 & 21,8 & 140 \\
\hline Fev. & 23,4 & 133 & 21,7 & 139 \\
\hline Mar. & 21,5 & 124 & 20,3 & 128 \\
\hline Abr. & 17,6 & 103 & 17,5 & 114 \\
\hline Maio & 14,7 & 103 & 14,5 & 107 \\
\hline Jun. & 12,3 & 126 & 12,8 & 157 \\
\hline Jul. & 12,5 & 141 & 12,9 & 161 \\
\hline Ago. & 13,3 & 123 & 13,6 & 165 \\
\hline Set. & 15,0 & 149 & 14,9 & 185 \\
\hline Out. & 17,5 & 131 & 17,0 & 156 \\
\hline Nov. & 20,1 & 112 & 18,9 & 140 \\
\hline Dez. & 22,7 & 105 & 20,7 & 144 \\
\hline TOTAIS & 214,6 & 1.465 & 206,6 & 1.736 \\
\hline
\end{tabular}

Fonte: ${ }^{1}$ INMET; ${ }^{2} \mathrm{CNPUV} / \mathrm{EMBRAPA}$ 
TABELA 3 - Maturação industrial e fenólica de uvas da variedade tinta Merlot, cultivadas nos municípios de Bento Gonçalves (BG) e Dom Pedrito (DP), safras de 2010 e 2011.

\begin{tabular}{|c|c|c|c|c|c|c|}
\hline \multirow{2}{*}{$\frac{\text { Safra }}{\text { Vinhedo }}$} & \multicolumn{3}{|c|}{2010} & \multicolumn{3}{|c|}{2011} \\
\hline & 1 & 2 & 3 & 1 & 2 & 4 \\
\hline Localização & DP & BG & BG & DP & BG & DP \\
\hline \multicolumn{7}{|c|}{ Maturação industrial } \\
\hline Acidez & $6,0 \mathrm{c}$ & $8,3 \mathrm{a}$ & $7,5 b$ & $4,3 \mathrm{f}$ & $5,7 \mathrm{~d}$ & $5,2 \mathrm{e}$ \\
\hline pH & $3,36 \mathrm{~b}$ & $3,27 \mathrm{~b}$ & $3,18 \mathrm{~d}$ & $3,65 \mathrm{a}$ & $3,11 \mathrm{c}$ & $3,67 \mathrm{a}$ \\
\hline${ }^{\circ}$ Brix & $19,0 \mathrm{~d}$ & $17,2 \mathrm{e}$ & $20,8 \mathrm{c}$ & $22,0 \mathrm{~b}$ & $18,5 \mathrm{~d}$ & $24,1 \mathrm{a}$ \\
\hline${ }^{\circ}$ Brix / acidez & 3,2 & 2,1 & 2,8 & 5,1 & 3,2 & 4,6 \\
\hline \multicolumn{7}{|c|}{ Maturação Fenólica } \\
\hline ApH1* & $262,3 \mathrm{c}$ & $522,0 \mathrm{a}$ & $522,7 \mathrm{a}$ & $372,1 b$ & $410,5 b$ & $189,3 d$ \\
\hline ApH3,2 & $176,1 b$ & $327,6 a$ & $369,0 \mathrm{a}$ & $220,5 b$ & $197,9 \mathrm{~b}$ & $147,7 \mathrm{~b}$ \\
\hline IMC\% & $30,3 b c$ & $37,3 \mathrm{~b}$ & $29,4 b c$ & $40,8 \mathrm{ab}$ & $51,8 \mathrm{a}$ & $22,1 \mathrm{c}$ \\
\hline IPT $_{\text {uva }}$ & $24,8 \mathrm{a}$ & $24,4 a$ & $28,0 \mathrm{a}$ & $20,1 \mathrm{~b}$ & $15,7 \mathrm{c}$ & $24,6 \mathrm{a}$ \\
\hline TC\% & $28,1 \mathrm{~b}$ & $53,8 \mathrm{a}$ & $52,7 \mathrm{a}$ & $46,6 \mathrm{a}$ & $50,6 \mathrm{a}$ & $23,8 b$ \\
\hline TS\% & $70,9 \mathrm{a}$ & $46,2 \mathrm{~b}$ & $47,3 b$ & $53,4 \mathrm{~b}$ & $49,4 \mathrm{~b}$ & $76,2 \mathrm{a}$ \\
\hline
\end{tabular}

* IPT - índice de polifenóis totais; ApH1 - antocianinas potenciais (mg.L-1 malvidina glucosídeo); ApH3,2 - antocianinas extraíveis (mg.L.-1 malvidina glucosídeo); IMC\% - índice de maturidade celular; TC\% - proporção de taninos nas cascas; TS\% - proporção de taninos nas sementes.

* Médias seguidas por mesma letra, na mesma linha, não diferem entre si, pelo teste de Tukey $(\mathrm{p}<0,05)$.

TABELA 4 - Compostos fenólicos em vinhos da variedade Merlot, provenientes de vinhedos localizados nos municípios de Bento Gonçalves (BG) e Dom Pedrito (DP), safras de 2010 e 2011.

\begin{tabular}{ccccccc}
\hline Safra & \multicolumn{3}{c}{$\mathbf{2 0 1 0}$} & & \multicolumn{3}{c}{$\mathbf{2 0 1 1}$} \\
\hline Vinhedo & $\mathbf{1}$ & $\mathbf{2}$ & $\mathbf{3}$ & $\mathbf{1}$ & $\mathbf{2}$ & $\mathbf{4}$ \\
\hline Localização & $\mathbf{D P}$ & $\mathbf{B G}$ & $\mathbf{B G}$ & $\mathbf{D P}$ & $\mathbf{B G}$ & $\mathbf{D P}$ \\
\hline FT* & $2.057,7 \mathrm{~ns}$ & $1.918,3$ & $2.040,2$ & $1.639,0$ & $1.551,9$ & $2.319,0$ \\
ANT & $228,1 \mathrm{~d}$ & $289,2 \mathrm{~cd}$ & $367,9 \mathrm{~cd}$ & $413,5 \mathrm{bc}$ & $569,6 \mathrm{ab}$ & $578,4 \mathrm{a}$ \\
PRO & $1,30 \mathrm{a}$ & $1,11 \mathrm{a}$ & $1,09 \mathrm{ab}$ & $1,13 \mathrm{a}$ & $0,44 \mathrm{~b}$ & $1,33 \mathrm{a}$ \\
IC & $3,94 \mathrm{~d}$ & $5,55 \mathrm{~cd}$ & $7,06 \mathrm{bc}$ & $7,22 \mathrm{bc}$ & $10,29 \mathrm{a}$ & $7,95 \mathrm{~b}$ \\
$\mathbf{\% C}$ & $28,9 \mathrm{~ns}$ & 27,3 & 32,5 & 27,3 & 34,3 & 35,0 \\
$\mathbf{\% M}$ & $43,9 \mathrm{~ns}$ & 47,4 & 36,4 & 47,9 & 42,8 & 44,1 \\
$\mathbf{\% P}$ & $27,2 \mathrm{ab}$ & $25,4 \mathrm{ab}$ & $31,1 \mathrm{a}$ & $24,8 \mathrm{ab}$ & $22,9 \mathrm{~b}$ & $21,0 \mathrm{~b}$ \\
TA & $3,53 \mathrm{~b}$ & $4,73 \mathrm{ab}$ & $6,22 \mathrm{ab}$ & $6,41 \mathrm{a}$ & $6,00 \mathrm{ab}$ & $5,21 \mathrm{ab}$ \\
IPT & $29,2 \mathrm{~d}$ & $37,0 \mathrm{c}$ & $46,5 \mathrm{ab}$ & $40,4 \mathrm{bc}$ & $39,6 \mathrm{bc}$ & $48,3 \mathrm{a}$ \\
\hline
\end{tabular}

* FT - fenóis totais (mg. $\mathrm{L}^{-1}$ ácido gálico); ANT - antocianinas (mg. $\mathrm{L}^{-1}$ malvidina glicosídeo); PRO - procianidinas (g.L $\mathrm{L}^{-1}$ cloreto de cianidina); IC - intensidade de cor; \% $\mathrm{C}$ - antocianinas copigmentadas; \% $\mathrm{M}$ - antocianinas monoméricas; \% $\mathrm{P}$ - antocianinas poliméricas; TA - antocianinas totais (unidades de absorbância); IPT - Índice de Polifenóis totais.

* Médias seguidas por mesma letra, na linha, não diferem entre si, pelo teste de Tukey ( $<<0,05)$. ns - diferença não significativa. 

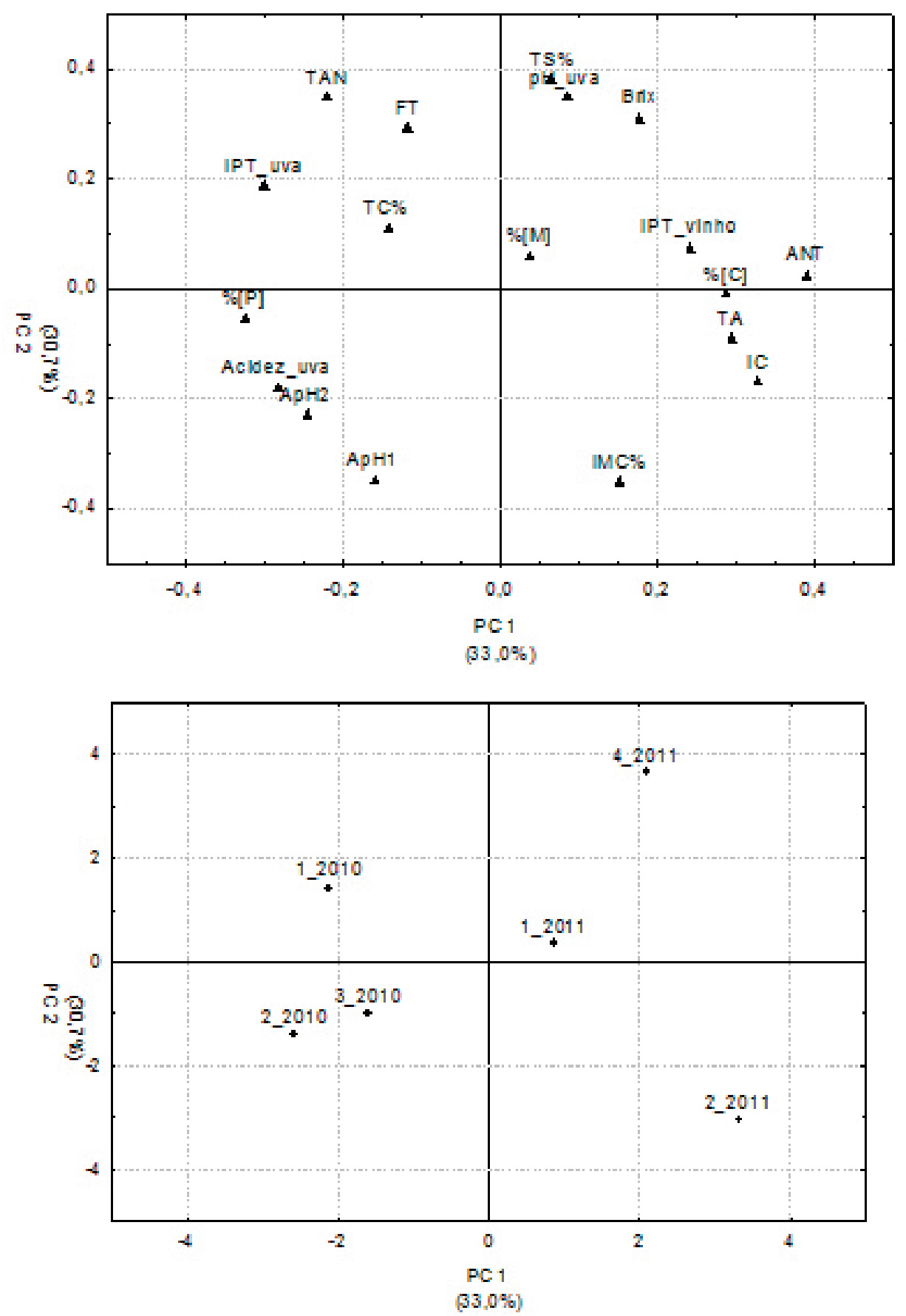

FIGURA 1 - Análise de Componente Principal dos parâmetros analisados nas uvas e vinhos da variedade Merlot, em quatro vinhedos e duas safras. (a) pesos das variáveis. (b) distribuição das amostras. Vinhedos 1 e 4 - localizados em Dom Pedrito; vinhedos 2 e 3 - localizados em Bento Gonçalves. * FT - fenóis totais (mg.L-1 ácido gálico); ANT - antocianinas (mg.L ${ }^{-1}$ malvidina glicosídeo); TAN - procianidinas (g. $\mathrm{L}^{-1}$ cloreto de cianidina); IC - intensidade de cor; $\% \mathrm{C}$ - antocianinas copigmentadas; $\% \mathrm{M}$ - antocininas monoméricas; $\% \mathrm{P}$ - antocianinas poliméricas; TA - antocianinas totais (unidades de absorbância); IPT - Índice de Polifenóis totais; ApH1 - antocianinas potenciais (mg. $\mathrm{L}^{-1}$ malvidina glicosídeo); $\mathrm{ApH} 3,2$ - antocianinas extraíveis (mg.L $\mathrm{L}^{-1}$ malvidina glicosídeo); IMC\% - índice de maturidade celular; TC\% proporção de taninos nas cascas; TS\% - proporção de taninos nas sementes. 
TABELA 5 - Coeficientes de correlação determinados nos vinhos e nas uvas, safra de 2010 e 2011.

\begin{tabular}{|c|c|c|c|c|c|c|}
\hline \multirow{2}{*}{ VINHO } & \multicolumn{6}{|c|}{ UVA } \\
\hline & IPT & ApH1 & ApH3,2 & TS\% & IMC\% & TC\% \\
\hline FT & $\mathbf{0 , 7 7}$ & $-0,41$ & $-0,07$ & 0,64 & $-0,91 *$ & 0,37 \\
\hline ANT & $-0,69$ & $-0,44$ & $-0,62$ & 0,21 & 0,30 & $-0,17$ \\
\hline TAN & $\mathbf{0 , 7 7}$ & $-0,40$ & $-0,05$ & 0,58 & $-0,87 *$ & 0,54 \\
\hline $\mathrm{IC}$ & $-0,65$ & 0,07 & $-0,15$ & $-0,26$ & 0,50 & $-0,18$ \\
\hline$\% \mathrm{C}$ & $-0,24$ & $-0,25$ & $-0,29$ & 0,20 & 0,01 & $-0,28$ \\
\hline$\% \mathrm{M}$ & $-0,43$ & $-0,24$ & $-0,40$ & 0,11 & 0,27 & $-0,02$ \\
\hline$\% \mathrm{P}$ & $\mathbf{0 , 7 0}$ & 0,50 & 0,72 & $-0,31$ & $-0,31$ & 0,31 \\
\hline $\mathrm{TA}$ & $-0,28$ & 0,11 & 0,04 & $-0,21$ & 0,17 & 0,13 \\
\hline $\mathrm{IPT}_{\text {vinho }}$ & 0,01 & $-0,07$ & 0,01 & 0,02 & $-0,21$ & 0,45 \\
\hline
\end{tabular}

* FT - fenóis totais (mg. $\mathrm{L}^{-1}$ ácido gálico); ANT - antocianinas (mg.L $\mathrm{L}^{-1}$ malvidina glicosídeo); TAN - taninos (g.L $\mathrm{L}^{-1}$ cloreto de cianidina); $\mathrm{IC}$ - intensidade de cor; $\% \mathrm{C}$ - antocianinas copigmentadas; $\% \mathrm{M}$ - antocianinas monoméricas; \% $\%$ antocianinas poliméricas; TA -

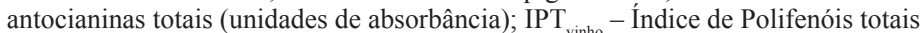

* IPT - índice de polifenóis totais; ApH1 - antocianinas potenciais (mg.L-1 malvidina glucosídeo); ApH3,2 - antocianinas extraíveis (mg. $\mathrm{L}^{-1}$ malvidina glicosídeo); IMC\% - índice de maturidade celular; TC \% - proporção de taninos nas cascas; TS\% - proporção de taninos nas sementes.

* Valor superior a 0,81 é significativo, a 5\% de probabilidade, pelo teste t.

\section{CONCLUSÕES}

A maturação industrial e fenólica tem uma grande variabilidade entre os vinhedos estudados, especialmente em relação ao conteúdo de antocianinas, deixando clara a influência da localização do vinhedo nas características das uvas, bem como a influência da safra.

O grau de maturação da uva, analisado através da \%IMC, influencia no conteúdo de compostos fenólicos totais e taninos encontrados nos vinhos resultantes.

A análise do potencial fenólico das uvas está correlacionada ao conteúdo de polifenóis, à porcentagem da cor devido a pigmentos poliméricos e à quantidade de procianidinas presentes nos vinhos resultantes, sendo assim uma ferramenta útil para a tomada de decisão do melhor momento da colheita.

A intensidade de cor, o conteúdo de antocianinas e a porcentagem de cor devido a antocianinas poliméricas nos vinhos, juntamente com o teor de polifenóis totais na uva foram os principais parâmetros que diferenciaram as uvas e os vinhos estudados.

\section{AGRADECIMENTOS}

Os autores agradecem a colaboração das vinícolas Dom Laurindo e Valmarino, de Bento Gonçalves; de Rigo Vinhedos e Irmãos Camponogora, de Dom Pedrito, pela cessão das amostras, e à Vinícola Velho Amâncio, pela cessão do espaço para a realização dos experimentos.

\section{REFERÊNCIAS}

BOULTON, R. B. A method for the assessment of copigmentation in red wines. In: ASEV ANNUAL MEETING, 47., 1996, Reno. Anais...

ĆURKO, N.; KOVAČEVIĆ GANIĆ, K.; GRACIN, L.; ĐAPIĆ, M.; JOURDES, M.; TEISSEDRE, PL. Characterization of seed and skin polyphenolic extracts of two red grape cultivars grown in Croatia and their sensory perception in a wine model medium. Food Chemistry, Berlin, v. 15, p. 145:15-22, 2014.

DAUDT, C. E.; MUTTI, L. S. M.; KERSTEIN, É. Possibilidades de produção de Vitis vinifera em Uruguaiana e vizinhanças. Ciência Rural, Santa Maria, v. 3, n. 1-4, p. 163-163, 1973. 
GLORIES, Y.; AUGUSTIN, M. Maturité phénolique du raisin, conséquences technologiques: application aux millésimes 1991 et 1992. Compte Rendu Colloque Journée Technqiue CIVB, Bordeaux, p.56-61, 1993.

GONZÁLEZ-NEVES, G. N.; FRANCO, J.; MOUTOUNET, M.; CARBONNEAU, A. Differentiation between Tannat, Merlot and CabernetSauvignon Uruguayan wines according their global polyphenolic composition. Journal International des Sciences de la Vigne et du Vin, Bordeaux, v. 40, n. 2, p.81-89, 2003.

HERNÁNDEZ-HIERRO, J. M.; QUIJADA-MORÍN, N.; MARTÍNEZ-LAPUENTE, L.; GUADALUPE, Z.; AYESTARÁN, B.; RIVAS-GONZALO, J. C.; SCRIBANO-BAILÓN, M. T. Relationship between skin cell wall composition and anthocyanin extractability of Vitis vinifera L. cv. Tempranillo at different grape ripeness degree. Food Chemistry, Berlin, v. 146, p. 41-47, 2014.

LASANTA, C.; CARO, I.; GÓMEZ, J.; PÉREZ, L. The influence of ripeness grade on the composition of musts and wines from Vitis vinifera $\mathrm{cv}$. Tempranillo grown in a warm climate. Food Research International, New York, v. 64, p. 432-438, 2014.

KENNEDY, J. A. Grape and wine phenolics: Observations and recent findings. Ciência e Investigación Agrária, Santiago, v. 35, n.2, p. 77 90, 2008.

MOTTA, F. S. Disponibilidade climática para maturação da uva destinada a produção de vinhos finos nas regiões da Serra do Nordeste e Campanha do Estado do Rio Grande do Sul. Revista Brasileira de Agrociência, Pelotas v. 9, n. 3, p. 297-299, 2003.

NOGALES-BUENO, J.; HERNÁNDEZ-HIERRO, J.M.; RODRÍGUEZ-PULIDO, F.J.; HEREDIA F.J. Determination of technological maturity of grapes and total phenolic compounds of grape skins in red and white cultivars during ripening by near infrared hyperspectral image: a preliminary approach. Food Chemistry, Berlin, v. 152, p. 586-591, 2014.
ORTEGA-REGULES, A.; BEL, A. Changes in skin cell wall composition during the maturation of four premium wine grape varieties. Journal of the Science of Food and Agriculture, London, v. 88, p. $420-428,2008$.

PSZCZÓlKOWSKI, P.; LECCO, C. C. Manual de vinificación: guia práctica para la elaboración de vinos. Santiago: Ediciones UC, p. 31-32, 2011.

RIBÉREAU-GAYON, P. et al. Handbook of enology: the chemistry of wine. $2^{\text {nd }}$ ed. Chichester: John Wiley and Sons, 2006. v.2, cap. 6, p. 141-203.

RIZZON, L. A.; ZANUZ, M. C.; MIELE, A. Evolução da acidez durante a vinificação de uvas tintas de três regiões vitícolas do Rio Grande do Sul. Ciência e Tecnologia de Alimentos, Campinas, v. 18, n. 2, p. 179-183, 1998.

SAINT-CRICQ, G. N.; VIVAS, N.; GLORIES, Y. Maturité phénolique: définitionet controle. Revue Francaise d'Oenologie, Paris, v. 6, n. 173, p. 22-25, 1998.

SPAYD, S. E.; TARARA, J.M.; MEE, D. L.; FERGUSON, J. C. Separation of Sunlight and Temperature Effects on the Composition of Vitis vinifera cv. Merlot Berries. American Journal of Enology and Viticulture, Davis, v. 3, n. 53, p.171182., 2002.

ZHANG, H.; FAN, P.; LIU, C.; WU, B.; LI, S.; LIANG, Z. Sunlight exclusion from Muscat grape alters volatile profiles during berry development. Food Chemistry, Berlin, v. 164, p. 242-260, 2014.

ZOECKLEIN, B. W.; FUGELSANG, K. C.; GUMP, B. H.; NURY, F. S. Análisis y producción de vino. Huesca: Acribia, 2001. 613p. 